\title{
A IMPORTÂNCIA DO DIMENSIONAMENTO DA CALHA INTERNA DE GRANDES COBERTURAS
}

\author{
THE IMPORTANCE OF INTERNAL GUTTER DIMENSIONING IN LARGE ROOFTOPS
}

\author{
Dabine Schmalz Richers ${ }^{1}$ \\ (DDaniel Setrak Sowmy ${ }^{2}$ \\ ${ }^{1}$ Instituto de Pesquisas Tecnológicas, São \\ Paulo, SP, Brasil, ssrichers@uol.com.br \\ 2 Instituto de Pesquisas Tecnológicas, São \\ Paulo, SP, Brasil, dss@ipt.br
}

Contribuição dos autores:

SSR: conceituação, curadoria de dados, análise formal, investigação, metodologia, administração de projetos, validação, visualização, escrita - rascunho original, escrita - revisão e edição. DSS: conceituação, curadoria de dados, análise formal, metodologia, administração de projetos, supervisão, validação,

visualização, escrita - revisão e edição.

Fomento: Não houve fomento Declaração de conflito: nada foi declarado.

Editor Responsável:

Guilherme Parsekian (D)

\begin{abstract}
Resumo
As intensidades pluviométricas assim como os valores de intensidade $x$ frequência $x$ duração (IFD) têm variado em razão das crescentes mudanças climáticas. Observa-se que, mesmo em regiões de precipitação pluviométrica aparentemente estável ou até baixa, têm ocorrido chuvas com IFD atípicas nunca vistas anteriormente. Desta forma, neste estudo, buscou-se descrever o dimensionamento do Sistema Sifônico de Drenagem de Águas Pluviais das calhas internas de grandes coberturas e de sua drenagem de emergência para poder identificar os impactos associados. Observou-se que as normas europeias, descrevem detalhadamente o dimensionamento de calhas internas, entre elas as mais usadas, as boxes gutters retangulares. A pesquisa bibliográfica realizada forneceu os parâmetros que fundamentam o dimensionamento de calhas internas. A NBR 10844:1989 fornece valores de precipitação pluviométrica para um período de retorno $\mathrm{T}=25$ anos, enquanto, para calhas internas, as normas $\mathrm{EN}$ 120563:2000 e DIN 1986-100:2008 exigem o uso de um período de retorno de $\mathrm{T}=100$ anos. Realizou-se um exercício projetual de dimensionamento de calhas internas conforme descrito nas normas EN 12056-3:2000, a DIN 1986-100:2008 e a literatura consultada permitindo destacar: i) o uso de fatores de segurança; ii) valores de precipitação pluviométrica com tempo de retorno de 100 anos; iii) as calhas internas devem ser dimensionadas com bordo livre, e iv) calhas internas devem apresentar uma drenagem de emergência. Muitos empreendimentos comerciais e industriais apresentam calhas internas não dimensionadas de acordo com as normas internacionais, sem drenagem de emergência. As falhas produzem transbordamentos e danos materiais às edificações são a consequência.
\end{abstract}

Palavras-chave: calhas Internas, dimensionamento, grandes coberturas.

\begin{abstract}
Rainfall intensities and intensity $x$ frequency $x$ duration (IFD) values have varied due to increasing climate change. It is observed that, even in regions with apparently stable or even low rainfall, there has been rainfall with atypical IFDs never seen before. Thus, in this study, we sought to describe the dimensioning of the Siphonic Stormwater Drainage System of the internal gutters of large roofs and their emergency drainage to identify the associated impacts. It was observed that the European standards describe in detail the design of internal gutters, including the most used, rectangular box gutters. The bibliographical research carried out provided the parameters that support the design of internal gutters. NBR 10844:1989 provides rainfall values for a return period $T=25$ years, while for internal gutters EN 12056-3:2000 and DIN 1986-100:2008 require the use of a return period of $T=100$ years. A design exercise was carried out for the design of internal gutters as described in EN 12056-3:2000, DIN 1986-100:2008 and the literature consulted, allowing to highlight: i) the use of safety factors; ii) rainfall values with a return time of 100 years; iii) internal gutters must be dimensioned with a freeboard, and iv) internal gutters must-have emergency drainage. Many commercial and industrial developments have internal gutters not dimensioned according to international standards without emergency drainage. Failures produce overflows, and material damage to buildings is the consequence.
\end{abstract}

Keywords: Internal gutters, dimensioning, large rooftops.

How to cite this article:

RICHERS, S. S.; SOWMY, D. S.. A importância do dimensionamento da calha interna de grandes coberturas. PARC Pesq. em Arquit. e Constr., Campinas, SP, v. 12, p. e021030, 2021. DOI: http://dx.doi.org/10.20396/parc.v12i00.8661111 


\section{Introdução}

A norma ABNT NBR 10.844 (ASSOCIAÇÃO BRASILEIRA DE NORMAS TÉCNICAS, 1989), aplicada no Brasil como referência para o dimensionamento de instalações de águas pluviais em edificações, menciona valores de intensidade pluviométrica em $\mathrm{mm} / \mathrm{h}$ para muitas localidades no Brasil, como citado em "Chuvas intensas no Brasil", de autoria de Otto Pfafstetter, publicada em 1957. Sabe-se que as intensidades pluviométricas assim como os importantes valores de IFD (intensidade $x$ frequência $x$ duração) têm variado muito em razão das crescentes mudanças climáticas (VERSTRATEN et. al., 2019). Observa-se que mesmo em regiões de precipitação pluviométrica aparentemente estável ou até baixa, têm ocorrido chuvas fortes com intensidade, frequência e duração atípicas, nunca vistas anteriormente.

As edificações comerciais e industriais tais como shopping center, centros de distribuição (galpões logísticos) e indústrias apresentam calhas externas e internas; muitas vezes por ocasião de ampliações uma calha externa passa a ser uma calha interna. A NBR 10.844:1989 não contempla o dimensionamento de calhas internas em edificações e recomenda o dimensionamento como qualquer outra calha não diferenciando entre calha externa e interna, utilizando-se as fórmulas e ábacos publicados neste artigo. Há várias publicações que descrevem danos ocorridos em edificações em virtude de falhas em suas calhas, normalmente por transbordamento (PIROGLU, 2014). Muitas dessas calhas são calhas internas, de formato retangular, tipo box gutter. As normas europeias EN 12.056-3 (DEUTSCHES INSTITUT FÜR NORMUNG, 2000) e DIN 1986-100 (DEUTSCHES INSTITUT FÜR NORMUNG, 2008), ao contrário da NBR 10.844:1989, descrevem detalhadamente o dimensionamento de calhas internas, entre elas, as mais usadas, as box gutters retangulares. A drenagem de águas pluviais das calhas externas e internas em edificações comerciais e industriais pode ocorrer pelo Sistema Convencional de Drenagem de Águas Pluviais (SCDAP) ou pelo Sistema Sifônico de Drenagem de Águas Pluviais (SSDAP).

A escolha do SCDAP ou SSDAP para uma calha externa é influenciado pela sua viabilidade econômica, pelo layout a ser adotado e possíveis características arquitetônicas e construtivas da edificação. Entretanto, nas calhas internas, o uso de SCDAP somente é tecnicamente viável se o uso de caixas de passagem internas na edificação for permitido ou se não há previsão de otimização de espaço em torno das prumadas ou uso de, por exemplo, pontes rolantes, ou se a configuração da edificação não exigir prumadas com condutores horizontais muito extensos.

Atualmente a tendência de construção de edificações com grandes coberturas como os centros de distribuição para áreas de $50.000 \mathrm{~m}^{2}$ até mais de $100.000 \mathrm{~m}^{2} \mathrm{com}$ uma ou mais calhas internas. Tais edificações podem apresentar comprimentos de mais de 400 m e larguras de "águas" de mais de 100 m. Além disso, por questões econômicas o vão livre da edificação é aproveitado até o seu limite: de um ou dois metros abaixo das calhas, não se permitindo prumadas verticais nem caixas de passagem internas. Esses empreendimentos permitem a estocagem em prateleiras e / ou usam pontes rolantes. Nesse contexto, este artigo busca compreender a importância do SSDAP para o dimensionamento da calha interna.

O Brasil registra nas últimas décadas um acentuado crescimento de empreendimentos industriais e comerciais demonstrado por três indicadores: i) a evolução do número de shoppings centers construídos; ii) o crescimento das indústrias automotivas; e iii) o surgimento dos parques logísticos. O SSDAP, segundo a norma VDI DIN 3806 (VEREIN DEUTSCHER INGENIEURE, 2000), é recomendável para coberturas acima de $5.000 \mathrm{~m}^{2}$. $O$ dimensionamento de calhas internas requer a observação de parâmetros que em 
calhas externas têm menor relevância. Numa calha interna, a largura e a profundidade são importantes, assim como a existência de um dreno de emergência ou de um sistema secundário de drenagem, além da observância de fatores de segurança. As dificuldades de dimensionamento de calhas internas decorrem entre outros pela forma construtiva dos telhados e uso de chapas de aço galvanizado de dimensões adequadas para a fabricação das calhas. O dimensionamento de calhas internas retangulares segundo a norma EN 12.056-3:2000 e DIN 1986-100:2008 será discutido detalhadamente neste artigo.

O objetivo deste artigo foi descrever o dimensionamento do SSDAP das calhas internas de grandes coberturas e de sua drenagem de emergência para poder identificar os impactos associados.

\section{Método}

A metodologia aplicada foi a revisão bibliográfica seguida de uma demonstração com estudos comparativos. Na revisão bibliográfica foram identificados e descritos sistemas, seus componentes, funcionamento e dimensionamentos associados propostos por referências para dimensionamento de calhas internas. Como demonstração foi realizado um exercício projetual. $\mathrm{Na}$ análise das normas nacionais e internacionais foi dada ênfase às que abordam e descrevem detalhadamente o dimensionamento de calhas internas com a utilização dos sistemas SCDAP e SSDAP. Foram identificados os autores nacionais e internacionais que estudam e pesquisam calhas internas em universidades e instituições de pesquisa.

No processo da revisão bibliográfica para este artigo, obteve-se o conhecimento que fundamenta o dimensionamento de calhas internas, publicado em revistas científicas, livros, dissertações, teses e rede eletrônica, no período de 1980 até 2020. Foram utilizados como termos de busca: calhas internas, dimensionamento, grandes coberturas, sistema sifônico de drenagem de águas pluviais. A revisão bibliográfica resultou em referências cujos focos dos trabalhos são: normas internacionais de dimensionamento manual e seus detalhes de cálculo. As principais normas utilizadas foram a EN 12.056-3:2000, DIN 1986-100:2008 e VDI 3806:2000, além dos trabalhos de Friedrich (2020) e Rickmann (2019).

As ilustrações deste artigo são oriundas das referências bibliográficas levantadas e do exercício projetual.

\section{Sistema Sifônico de Drenagem de Águas Pluviais}

\section{Descrição}

O sistema sifônico diferencia-se do convencional pela maior diferença de altura entre o ponto de captação das águas pluviais, sendo que essa diferença de altura constitui a sua força motora. No sistema convencional a diferença de altura é pequena, conforme visualizado na Figura 1 que sintetiza os sistemas de drenagem abordados.

O Sistema Sifônico de Drenagem de Águas Pluviais (SSDAP) é um sistema de captação de águas pluviais para grandes coberturas, com pé-direito acima de 3,5 m. Esse sistema foi descrito, inicialmente, na Suécia e Finlândia no final dos anos 70 pelos pesquisadores Olavi Ebeling e Risto Lunden (BRAMHALL, 2005). Segundo Arthur e Swaffield (1999) e May (2004), o sistema sifônico opera por pressão negativa pelo princípio de Bernoulli, enquanto que o Sistema Convencional de Drenagem de Águas Pluviais (SCDAP) funciona por gravidade. O sistema sifônico é formado por um conjunto de ralos sifônicos, componentes especiais projetados e dimensionados para a 
RICHERS, S. S.; SOWMY, D. S.

A importância do dimensionamento da calha interna de grandes coberturas

captação das águas pluviais, por tubos condutores horizontais e verticais, conexões e ferragens especiais conforme mostrado na Figura 2.

Figura 1 - Layout dos sistemas convencionais e sifônicos

a) convencional (por gravidade)

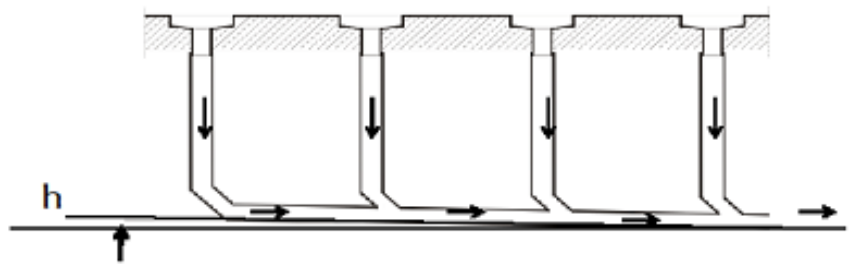

b) sifônico (por pressão negativa)

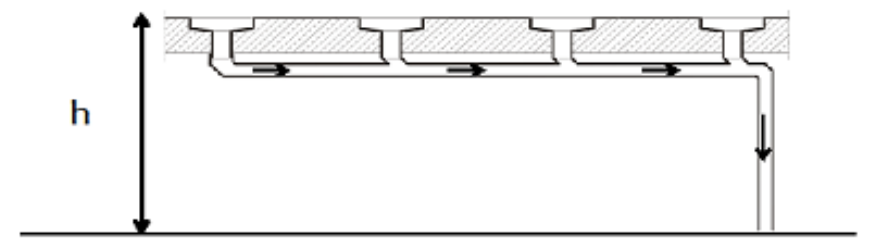

Fonte: Traduzido de Friedrich (2020).

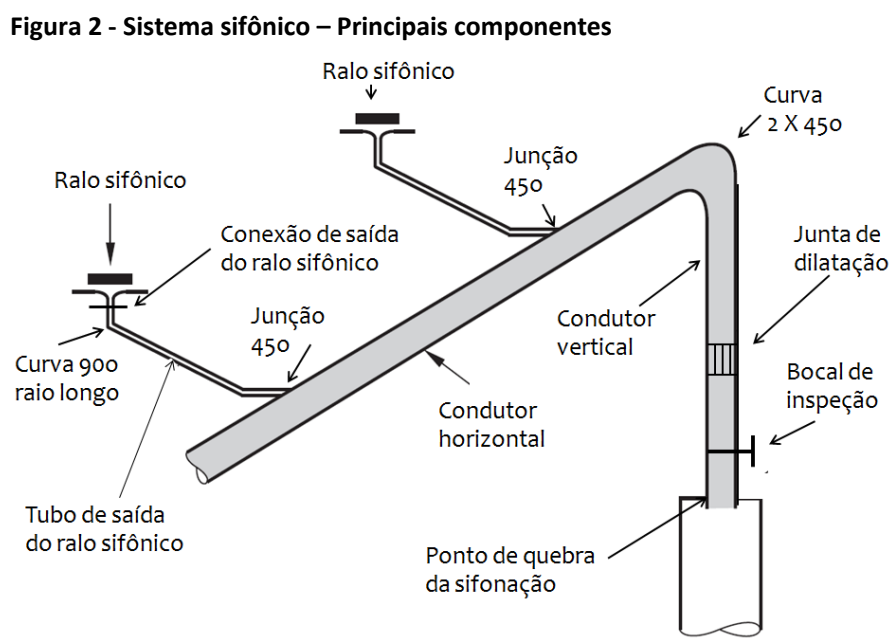

Fonte: Traduzido de BS 8490 (BRITISH STANDARDS INSTITUTE, 2007).

A norma da American Society of Plumbing Engineers ASPE 45 (AMERICAN SOCIETY OF MECHANICAL ENGINEERS, 2018) descreve como condutor horizontal (collector pipe) o tubo horizontal instalado abaixo da cobertura ou da calha que recebe o escoamento de água proveniente dos tubos de saída dos ralos sifônicos (tailpipe). O condutor vertical (downpipe) conecta o condutor horizontal com o ponto de saída do sistema sifônico. A ASPE 45:2018 denomina de ponto de quebra de pressão atmosférica o ponto onde o condutor vertical apresenta pressão interna igual à pressão atmosférica (siphon break). A partir desse ponto termina a sifonação.

\section{Funcionamento}

O funcionamento do sistema sifônico é por pressão negativa na faixa de -100 até -850 mbar. O sistema apresenta tubos com enchimento quase total (95\% até 97\%), não precisa de inclinação nos condutores horizontais e apresenta velocidades de escoamento de 6 até $7 \mathrm{~m} / \mathrm{s}$ (norma ASPE 45:2018). Tipicamente são usados tubos e conexões em polietileno de alta densidade (PEAD) ou ferro fundido. 
RICHERS, S. S.; SOWMY, D. S.

A importância do dimensionamento da calha interna de grandes coberturas

Os ralos sifônicos são a base do sistema de engenharia que caracteriza o sistema sifônico. O corpo do ralo sifônico é formado de aço inoxidável ou resina (por exemplo PEAD), seguido de uma grelha de aço ou PEAD para a retenção de detritos maiores. Há ainda um defletor antivórtice em forma de disco com função de auxiliar na desaeração do sistema e evitar a entrada de ar. A Figura 3 mostra o defletor antivórtice, o tubo de saída do ralo sifônico e o condutor horizontal.

Figura 3 - Sistema sifônico - Captação de água pluvial com ralo sifônico

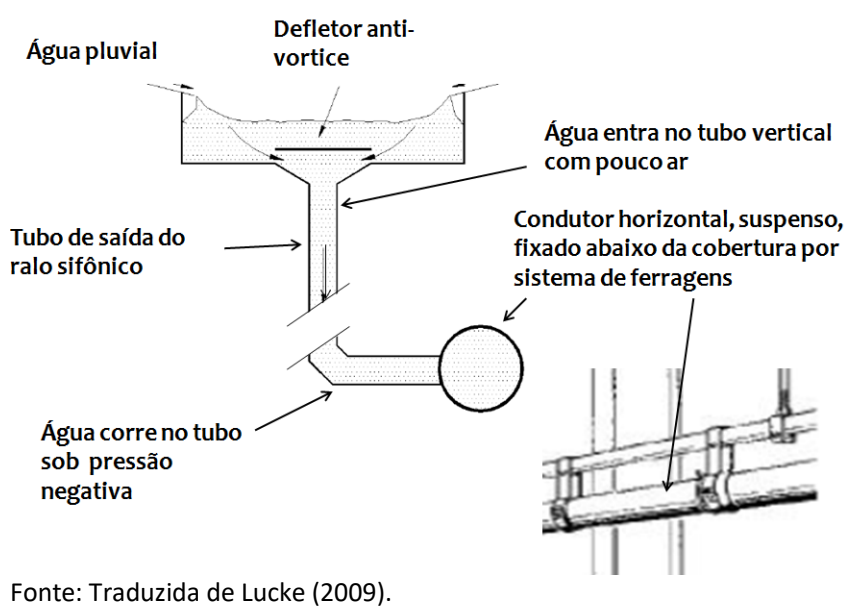

Na Figura 4 (esquerda), é visualizado um ralo sifônico e o condutor horizontal em processo de enchimento parcial, com uma mistura de água e ar. Na Figura 4 (direita), é mostrado um ralo sifônico com o dispositivo antivórtice e a grelha, sendo que a tampa superior do ralo foi retirada para melhor visualização. O sistema sifônico está em regime de vazão de projeto quando todo o ar é expulso das tubulações horizontais e verticais. Na Figura 5 (esquerda) verifica-se que ainda há ar acumulado e que deve ser eliminado rapidamente, conforme é visualizado na Figura 5 (direita).

Figura 4 - Sistema sifônico: enchimento parcial do condutor horizontal (esquerda) e ralo sifônico com dispositivo antivórtice e grelha (direita)
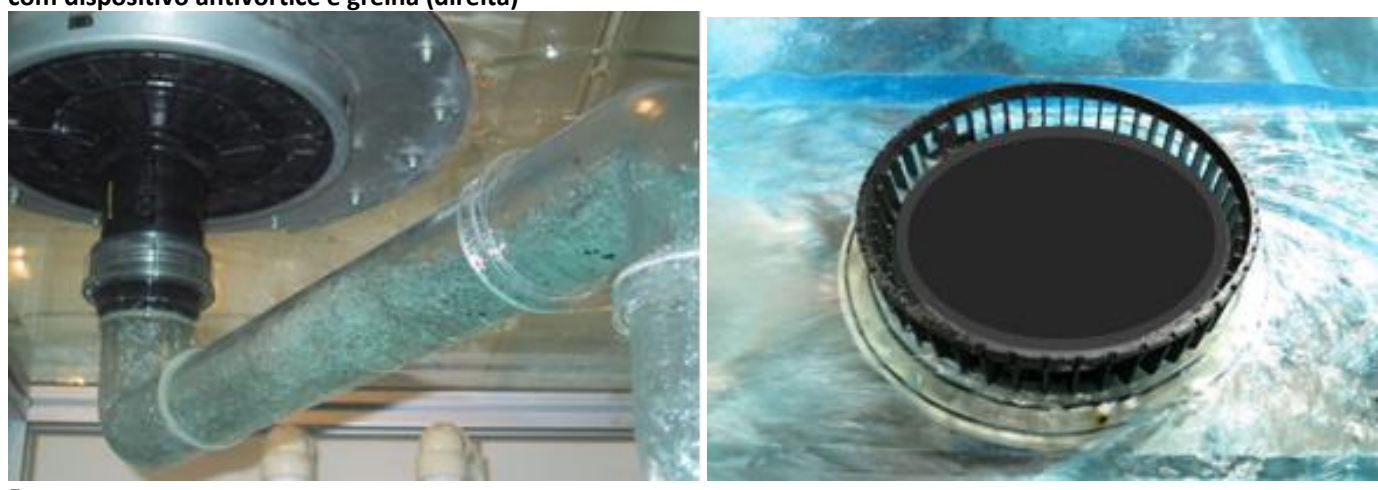

Fonte: os autores. 
RICHERS, S. S.; SOWMY, D. S.

A importância do dimensionamento da calha interna de grandes coberturas

Figura 5 - Sistema sifônico - ar acumulado no interior de tubo quase cheio (esquerda) e tubo completamente cheio (direita)

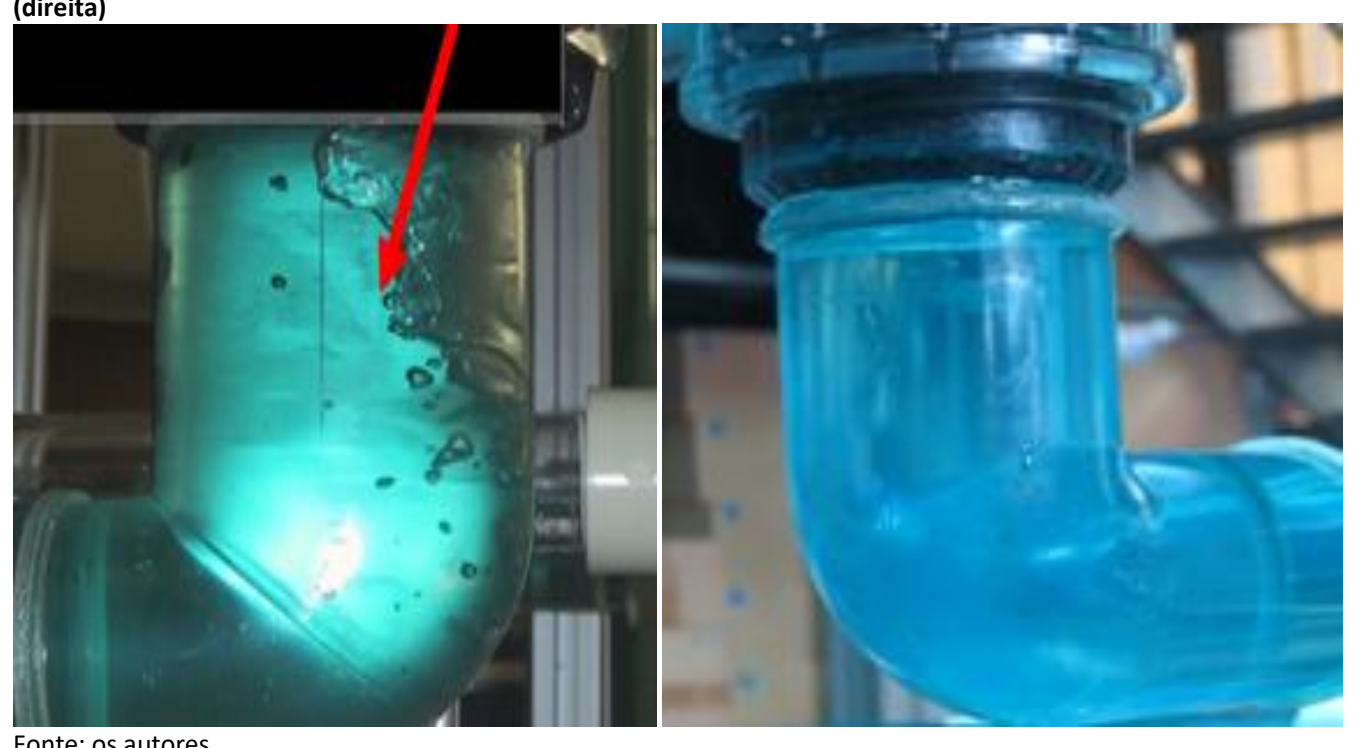

O SSDAP é dimensionado por software e têm os seus parâmetros de dimensionamento determinados pelas normas internacionais que regem este tipo de drenagem de águas pluviais:

- BS 8490:2007 - Guide to Siphonic Roof Drainage Systems (BRITISH STANDARDS INSTITUTE, 2007);

- VDI DIN 3806:2000 - Roof Drainage with Siphonic System (VEREIN DEUTSCHER INGENIEURE, 2000);

- ASPE 45:2013 - Siphonic Roof Drainage (AMERICAN SOCIETY OF MECHANICAL ENGINEERS, 2018);

- ASME A.112.6.9:2005 - Siphonic Roof Drains (AMERICAN SOCIETY OF MECHANICAL ENGINEERS, 2005);

- ASTM F 2021:2006 - Standard Guide for Design and Installation of Plastic Siphonic Roof Drainage Systems (AMERICAN SOCIETY FOR TESTING MATERIALS, 2006);

- Capítulo 16 "Siphonic Roofwater Systems" no "Water Sensitive Urban Design Technical Manual" do Governo da Australiano (DEPARTAMENT OF PLANNING AND LOCAL GOVERNMENT, 2010).

Os principais parâmetros de dimensionamento estão agrupados na Quadro 1.

A equação principal de um sistema sifônico é a equação de Bernoulli modificada (AMERICAN SOCIETY OF PLUMBING ENGINEERS, 2018, p.12), Equação 1, a seguir:

$$
\frac{P i}{\rho g}+\frac{V i^{2}}{2 g}+Z i=\frac{P e}{\rho g}+\frac{V e^{2}}{2 g}+Z e+\sum_{j=1}^{m}(h f) j+\sum_{k=1}^{n}(h t) k
$$

onde,

$$
\begin{aligned}
& P=\text { pressão estática, em mca; } \\
& \rho=\text { densidade do fluido, em } \mathrm{kg} / \mathrm{cm}^{3} ;
\end{aligned}
$$


RICHERS, S. S.; SOWMY, D. S.

A importância do dimensionamento da calha interna de grandes coberturas

$$
\begin{aligned}
& \mathrm{g}=\text { aceleração da gravidade de } 9,8 \mathrm{~m} / \mathrm{s}^{2} ; \\
& V=\text { velocidade do fluido, em } \mathrm{m} / \mathrm{s} ; \\
& \mathrm{Z}=\text { cota do fluido, em } \mathrm{m} ; \\
& \mathrm{h}_{\mathrm{f}}=\text { perda de carga devido à resistência de fluxo, em mca; } \\
& \mathrm{k}=\text { valor de resistência, adimensional; } \\
& \mathrm{i}=\text { ponto de entrada no sistema, ou seja, ralo sifônico, e } \\
& \text { e = ponto de saída no sistema. }
\end{aligned}
$$

\begin{tabular}{|c|c|c|}
\hline Parâmetros & Valores & Fonte \\
\hline \multicolumn{3}{|c|}{ Projeto: } \\
\hline Verificação da perda de carga por prumada & Máximo $10 \%$ ou $1,0 \mathrm{~m}$ & BS 8490:2007 / ASPE 45:2013 \\
\hline Fator de segurança & $10 \%$ na vazão do projeto & ASPE 45:2013 \\
\hline Pressão negativa & Máxima -900mbar & VDI 3806:2000 \\
\hline Condutor vertical & $\begin{array}{c}\text { Comprimento mínimo } 4,0 \mathrm{~m} \text {; diâmetro igual ou } \\
\text { menor do que o tubo horizontal; apresentar no } \\
\text { topo duas curvas } 450\end{array}$ & VDI 3806:2000 / ASPE 45:2013 / BS 8490:2007 \\
\hline Tubo de saída do ralo sifônico & $\begin{array}{l}\text { Mínimo } 1,0 \mathrm{~m} \text { de comprimento, curva } 90^{\circ} \text { na } \\
\text { parte inferior }\end{array}$ & VDI 3806:2000 / ASPE 45:2013 \\
\hline Velocidades no sistema sifônico & $\begin{array}{c}\text { Tubos, mínimo } 1,0 \mathrm{~m} / \mathrm{s} \text {, máximo } 6-7 \mathrm{~m} / \mathrm{s} \text {, tubo } \\
\text { vertical de saída } 2,5-3,0 \mathrm{~m} / \mathrm{s}\end{array}$ & VDI 3806:2000 / ASPE 45:2013 / BS8490:2007 \\
\hline Tempo de enchimento & Máximo 60s & BS 8490:2007 \\
\hline \multicolumn{3}{|c|}{ Calhas: } \\
\hline Inclinação e tamanho & $\begin{array}{l}\text { Até } 1 \% \text { de inclinação, capacidade da vazão de } \\
\text { projeto }\end{array}$ & ASPE 45:2013 / BS 8490:2007 \\
\hline \multicolumn{3}{|c|}{ Ralos Sifônicos: } \\
\hline Posicionamento & $\begin{array}{l}\text { Distância máxima } 20 \mathrm{~m} \text {, equidistante um do } \\
\text { outro e mínimo de dois ralos por calha }\end{array}$ & VDI 3806:2000 / BS 8490:2007 \\
\hline \multicolumn{3}{|c|}{ Sistema secundário ou extravasores: } \\
\hline Segurança & $\begin{array}{l}\text { Exigência de extravasor ou sistema secundário } \\
\text { com vazão adequada }\end{array}$ & BS 8490:2007 / Chapter 16:2010 \\
\hline \multicolumn{3}{|c|}{ Tubulação: } \\
\hline Espessura das paredes & Mínimo para PEAD é Schedule 40 & ASPE 45:2013 / ASTM F 2021:2006 \\
\hline \multicolumn{3}{|c|}{ Operação: } \\
\hline Limpeza e caixas de passagem & $\begin{array}{c}\text { Mínimo 3-4 vezes / ano; caixas de passagem } \\
\text { com grelha para ventilação }\end{array}$ & BS 8490:2007 / ASPE 45:2013 \\
\hline
\end{tabular}

O dimensionamento é feito na Fase $\mathrm{C}$. O dimensionamento manual de um sistema sifônico deve seguir as etapas: (Etapa 1) cálculo da vazão; (Etapa 2) determinação da quantidade de ralos sifônicos; (Etapa 3) determinação do layout da prumada; (Etapa 4) cálculo da pressão estática disponível; (Etapa 5) cálculo da perda de carga preliminar; (Etapa 6) determinação dos diâmetros dos tubos e velocidades da água; (Etapa 7) cálculo da perda de carga real; (Etapa 8) cálculo das pressões negativas e (Etapa 9) verificação do dimensionamento.

A elaboração de um projeto de sistema sifônico requer a observância de quatro fases distintas e sucessivas: Fase A - Informações da edificação e localidade; Fase B Cálculos preliminares; Fase $C$ - Dimensionamento do projeto e Fase $D$ - Informações detalhadas para a instalação.

\section{Instalações comerciais e industriais}

Nas Figuras 6, 7 e 8 são mostrados detalhes de instalações comerciais e industriais. $\mathrm{Na}$ Figura 6, visualiza-se um ralo sifônico e a sua conexão com o condutor horizontal. 
RICHERS, S. S.; SOWMY, D. S.

A importância do dimensionamento da calha interna de grandes coberturas

Figura 6 - Sistema sifônico - Ralo sifônico com o condutor horizontal

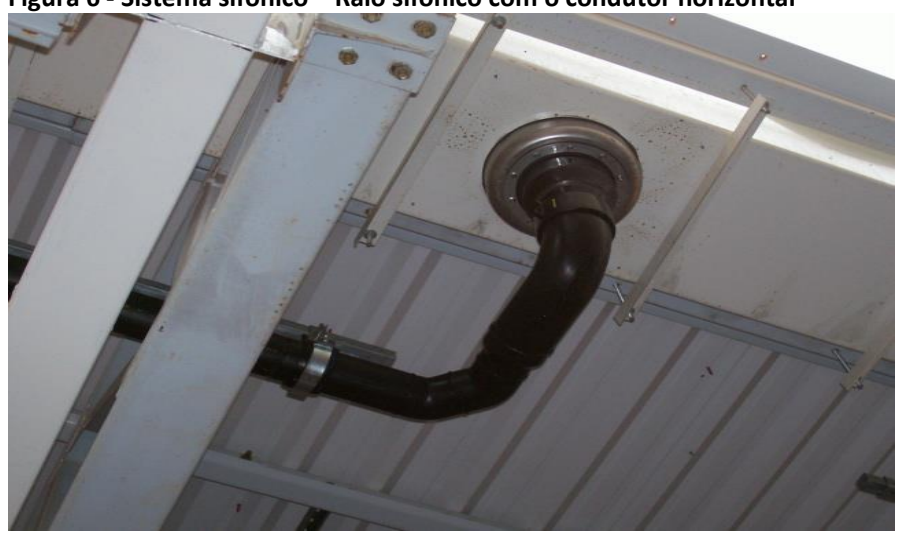

Fonte: os autores.

Na Figura 7, é mostrado um condutor horizontal instalado abaixo da calha de água pluvial e atravessando o prédio, num detalhe de instalação típico do sistema sifônico.

Figura 7 - Sistema sifônico - Condutor horizontal

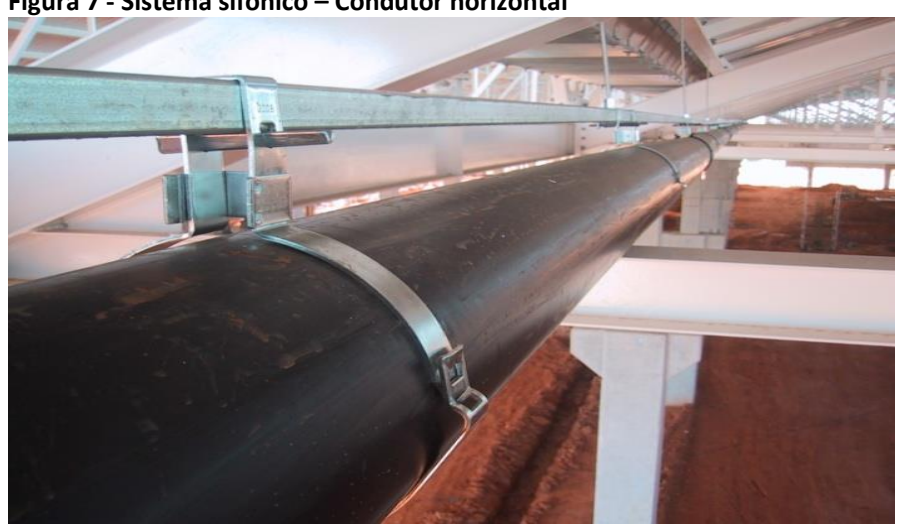

Fonte: os autores.

Na Figura 8, é mostrada a parte inferior de um condutor vertical, com um bocal de inspeção.

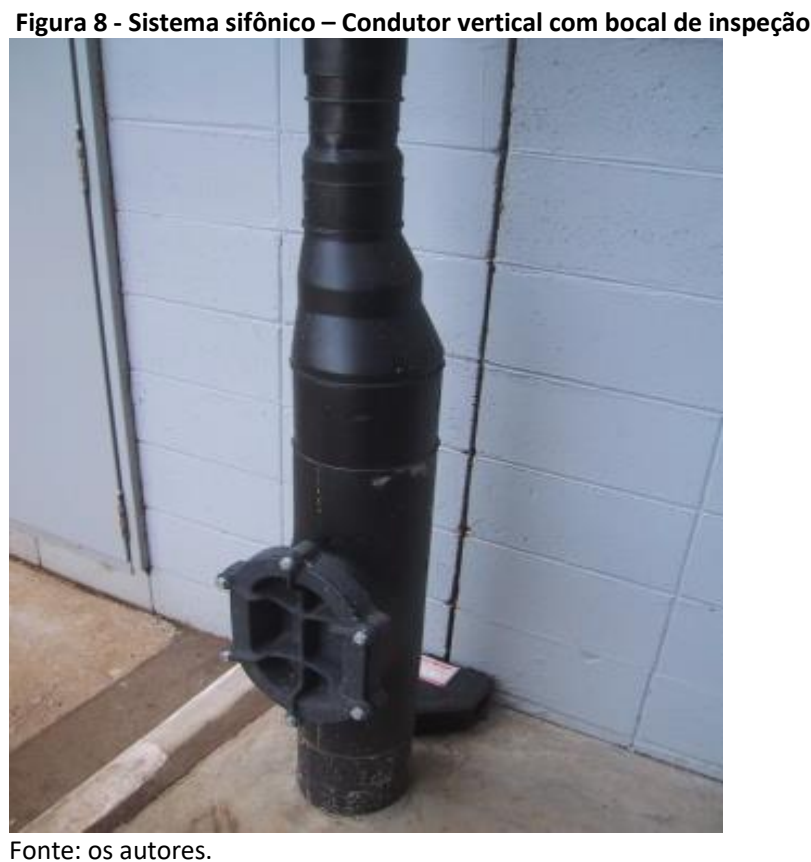


RICHERS, S. S.; SOWMY, D. S.

A importância do dimensionamento da calha interna de grandes coberturas

\section{Aplicabilidade}

Os estudos e publicações de May (1997), Bramhall e Saul (1998), Bowler e Arthur (1999), Sommerhein (1999), Rattenbury (2001), May (2004), Arthur e Wright (2007), Beecham e Lucke (2012), Richers (2018) e Richers e Sowmy (2019) permitem afirmar que o sistema sifônico apresenta os seguintes benefícios em relação ao sistema convencional: (i) quantidade menor de prumadas; (ii) menor quantidade de caixas de passagem; (iii) menor diâmetro dos tubos nas prumadas; (iv) drenagem de calhas internas sem utilizar caixas de passagem e (v) tubulação sem inclinação.

Conforme Pereira (2012), na Figura 9, visualizam-se duas curvas de evolução qualitativa dos custos totais de um sistema convencional e sistema sifônico com relação à área da cobertura. Ainda segundo o autor, apesar dos custos menores do sistema convencional, haverá um ponto no qual, de acordo com a área, diâmetro dos tubos e vazões, além dos outros custos que compõem os sistemas de drenagem de águas pluviais, em que os custos se igualam. A partir desse ponto, o sistema sifônico poderá ter custos menores.

Figura 9- Curva de evolução dos custos dos sistemas de drenagem, de acordo com a área de cobertura CUSTOTOTAL

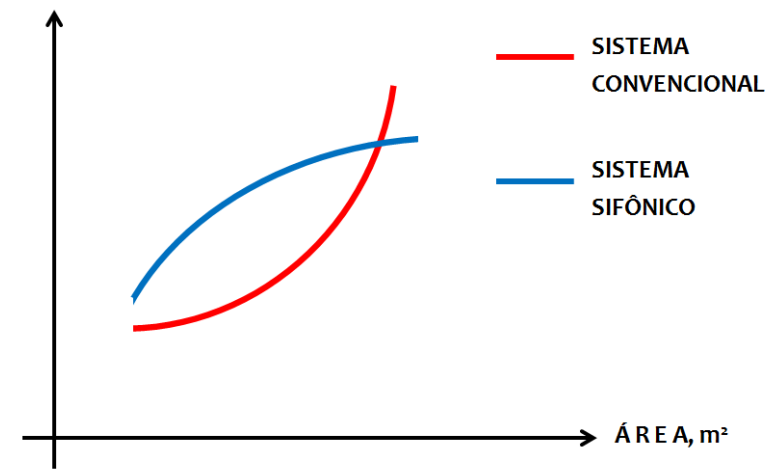

Fonte: Pereira (2012).

\section{Dimensionamento de calhas internas}

O dimensionamento de calhas internas pode ser mostrado no exemplo de um galpão de quatro "águas" drenadas pelo sistema convencional (SCDAP) na Figura 10 (esquerda) e comparativamente pelo sistema sifônico (SSDAP) na Figura 10 (direita).

Figura 10 - Captação com calhas: SCDAP (esquerda) e SSDAP (direita)
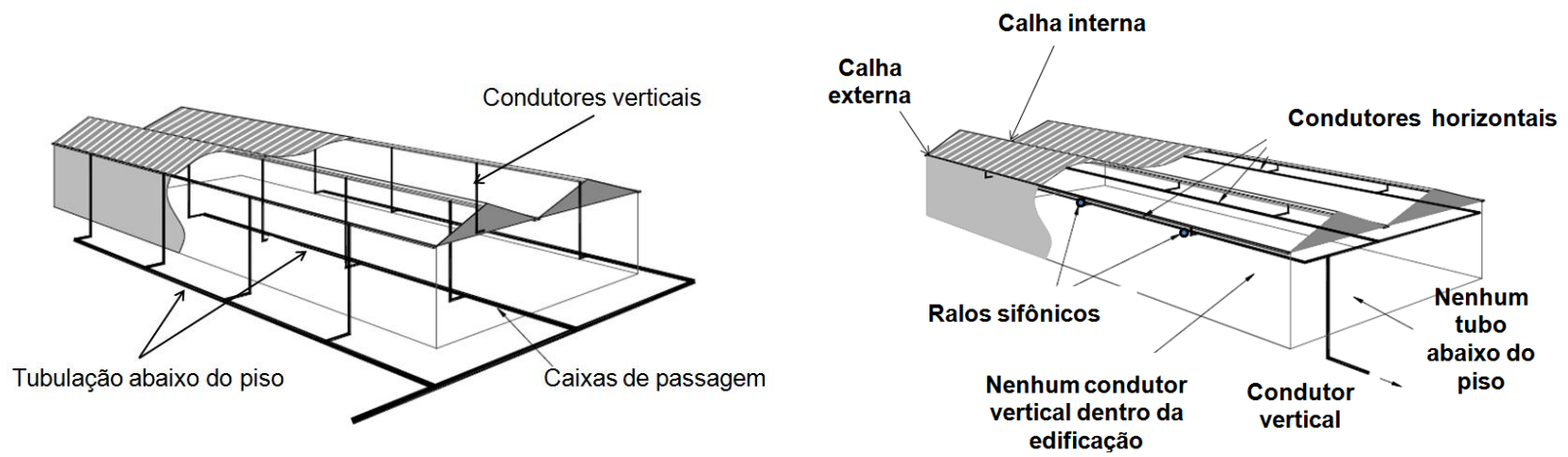

Fonte: Traduzida de Lucke (2009). 
RICHERS, S. S.; SOWMY, D. S.

A importância do dimensionamento da calha interna de grandes coberturas

A EN 12.056-3:2000 e DIN 1986-100:2008 recomendam que todas as calhas internas tenham saídas de emergência, nos seus extremos ou internamente por dispositivos dimensionados para este fim, por exemplo, ralos sifônicos ou convencionais. Além disso, devem ser dimensionadas com intensidade pluviométrica de duração de cinco minutos e intensidade máxima ocorrida em 100 anos $\left(\mathrm{r}_{5 / 100}\right)$. A capacidade das saídas de emergência deve ser dimensionada de acordo com as necessidades da edificação, variando em muitos casos entre $30-50 \%$ da capacidade da vazão de projeto do sistema de drenagem de águas pluviais. Em alguns países, como a Austrália, o sistema de emergência deverá ter 100\% da vazão de projeto (norma AS/NZS 3500.3: 2015).

A calha interna, segundo Rickmann (2019) e Friedrich (2020) deverá apresentar um fluxo de água pluvial de três alturas distintas, conforme mostrado na Figura 11.

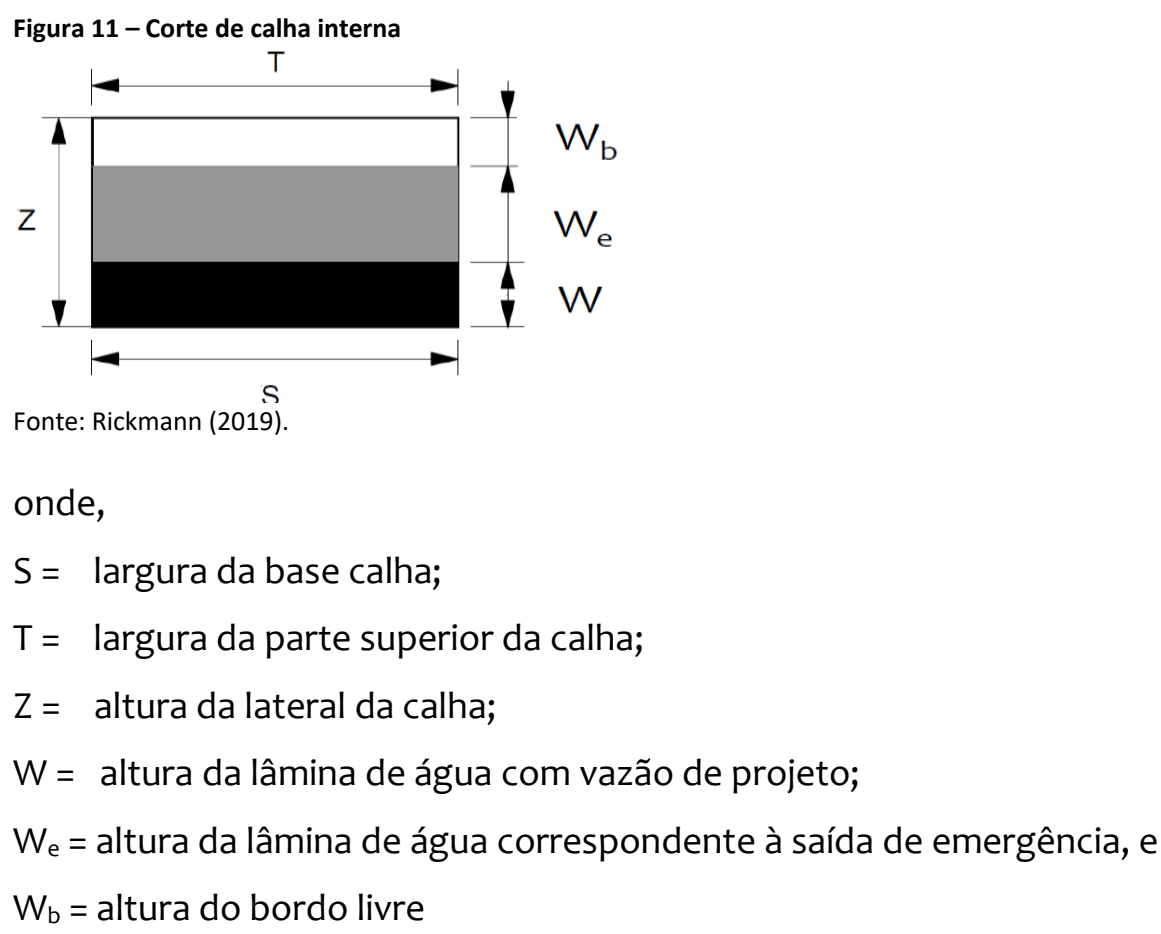

Fonte: Rickmann (2019).

onde,

$\mathrm{S}=$ largura da base calha;

$\mathrm{T}=$ largura da parte superior da calha;

$\mathrm{Z}=$ altura da lateral da calha;

W = altura da lâmina de água com vazão de projeto;

$\mathrm{W}_{\mathrm{e}}=$ altura da lâmina de água correspondente à saída de emergência, e

$\mathrm{W}_{\mathrm{b}}=$ altura do bordo livre

A norma DIN 1986-100 (DEUTSCHES INSTITUT FÜR NORMUNG, 2008, p. 73) estabelece valores mínimos para a altura de "W", Tabela 1.

Tabela 1 - Alturas mínimas, em $\mathrm{mm}$, para o bordo livre

\begin{tabular}{cc}
\hline Altura total, "W"em mm & Bordo livre, em mm \\
\hline$<85$ & 25 \\
\hline $85-250$ & $0,3 \times \mathrm{W}$ \\
\hline$>250$ & 75 \\
\hline
\end{tabular}

Fonte: Norma DIN 1986-100 (DEUTSCHES INSTITUT FÜR NORMUNG, 2008 p.73).

A altura da lâmina de águas W corresponde à maior altura na vazão de projeto, decrescendo em direção ao ralo convencional ou sifônico conforme a Figura 12.

Figura 12 - Variação do perfil da lâmina de água numa calha

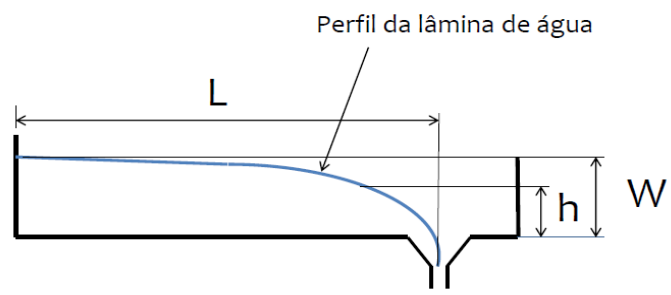

Fonte: Adaptado de Friedrich (2020). 
RICHERS, S. S.; SOWMY, D. S.

A importância do dimensionamento da calha interna de grandes coberturas

onde,

$\mathrm{L}=$ trajeto percorrido pela água até o ralo;

$\mathrm{h}=$ altura da lâmina de água retida em função do ralo, e

$\mathrm{W}$ = altura da lâmina de água, idem $\mathrm{W}_{\mathrm{e}}$ e $\mathrm{W}_{\mathrm{b}}$ (Figura 11)

A altura da lâmina de água "h" no ralo está interligada com a altura "W" através do Fator "Fh". Para calhas retangulares segue:

$$
\mathrm{W}=\mathrm{h} / \mathrm{F}_{\mathrm{h}}
$$

Equação (2)

onde,

$\mathrm{h}=$ altura da lâmina de água retida em função do ralo;

$\mathrm{W}$ = altura da lâmina de água, idem $\mathrm{W}_{\mathrm{e}}$ e $\mathrm{W}_{\mathrm{b}}$;

$\mathrm{F}_{\mathrm{h}}=$ fator de pressão, $\mathrm{e}$

$$
\mathrm{F}=0,1766 \times(\mathrm{S} / \mathrm{T})^{2}-03498 \times(\mathrm{S} / \mathrm{T})+0,6458
$$

Equação (3)

onde,

$\mathrm{S}=$ largura da base calha, $\mathrm{e}$

$\mathrm{T}=$ largura da parte superior da calha.

Assim sendo, para calhas retangulares "W" aproximadamente igual ao dobro da altura " $h$ ". No dimensionamento da calha interna, os valores das alturas de "W", "We" e " $\mathrm{W}_{\mathrm{b}}$ " devem ser calculados separadamente e adicionados para a altura final mínima necessária. A norma EN 12056-3:2000 e DIN 1986-100:2008 recomendam a utilização de fatores de segurança no dimensionamento de calhas, nos casos em que a precipitação pluviométrica " $r$ " não seja conhecida ou quando tratar de calhas em edificações de alto valor agregado, como por exemplo um centro de distribuição. A Tabela 2 detalha alguns fatores de segurança "SF".

\begin{tabular}{|c|c|}
\hline Situação & Fator de segurança \\
\hline Calhas externas. & 1,0 \\
\hline $\begin{array}{l}\text { Calhas externas, onde o transbordamento de águas pluviais possa causar danos, por exemplo, } \\
\text { entradas de prédios públicos. }\end{array}$ & 1,5 \\
\hline $\begin{array}{c}\text { Calhas internas, ou qualquer outro local onde o transbordamento pode levar águas pluviais ao } \\
\text { interior da edificação. }\end{array}$ & 2,0 \\
\hline $\begin{array}{l}\text { Calhas internas em locais onde é necessário um cuidado excepcional como: hospitais, teatros, } \\
\text { depósitos e lugares onde a entrada de água pode formar gases tóxicos ou inflamáveis, e edificações } \\
\text { como museus. }\end{array}$ & 3,0 \\
\hline \multicolumn{2}{|l|}{ Fonte: EN 12056-3 (DEUTSCHES INSTITUT FÜR NORMUNG, 2000, p.5). } \\
\hline $\begin{array}{l}\text { É importante destacar que para um hospital, conforme Figura } 13 \\
\text { instalação), com base na Tabela } 2 \text {, o fator de segurança a ser } \\
\text { dimensionamento de uma calhainterna deve ser de SF=1.5. }\end{array}$ & $\begin{array}{l}3 \text { (detalhe de } \\
\text { r adotado no }\end{array}$ \\
\hline
\end{tabular}

Tabela 2 - Fatores de segurança para correção da intensidade pluviométrica " $r$ " 
RICHERS, S. S.; SOWMY, D. S.

A importância do dimensionamento da calha interna de grandes coberturas

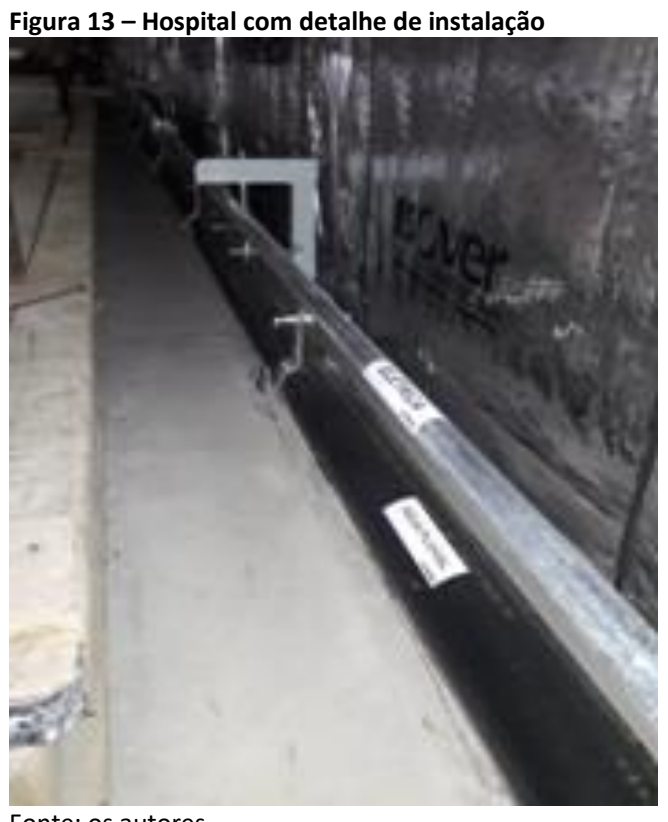

Fonte: os autores.

Os fatores de segurança "SF" devem ser usados no cálculo da vazão de projeto no dimensionamento de uma calha, conforme a Equação 4:

$$
Q=r . A . C . S F
$$

onde

$\mathrm{Q}$ = vazão em $\mathrm{L} / \mathrm{s}$;

$\mathrm{r}$ = intensidade pluviométrica, em $\mathrm{L} /\left(\mathrm{s} . \mathrm{m}^{2}\right)$;

$\mathrm{A}$ = área relevante do telhado, em $\mathrm{m}^{2}$, já corrigida em relação à inclinação;

$C=$ fator de escoamento, adimensional, normalmente 1,0 quando não outras informações contrárias, e

$\mathrm{SF}=$ fator de segurança

A drenagem de águas pluviais numa calha depende de fatores tais como (Friedrich, 2020):

- $\quad$ seção da calha (área), a vazão aumenta com o aumento da seção;

- forma (retangular, trapezoidal, redonda), calhas profundas têm maior vazão, com a mesma seção do que calhas menos profundas, devido à pressão hidráulica maior;

- comprimento até os ralos, a vazão diminuiu com o aumento do trajeto devido à fricção;

- inclinação, a vazão aumenta com a inclinação;

- direção, a mudança de direção diminui a velocidade e a vazão;

- vento e,

- mudanças climáticas e de tempo.

O dimensionamento de uma calha segundo a EN 12056-3:2000 e DIN 1986-100:2008 deve ser efetuado em duas etapas, sendo a primeira o cálculo da vazão Q $\llcorner$ usando-se a área da seção da calha e a segunda inclui a inclinação da calha e o seu comprimento. Assim, na primeira etapa: 


$$
Q_{L}=0,9 \times 3,89 \times 10^{-5} \times A_{w}^{1,25} \times F_{o} \times F_{S}
$$

onde,

$\mathrm{Q}_{\mathrm{L}}=$ vazão da calha em $\mathrm{L} / \mathrm{S}$;

$A_{w}=$ seção molhada da calha (altura da lâmina de água x largura da calha);

$\mathrm{F}_{\mathrm{o}}=$ fator de profundidade, $\mathrm{e}$

$\mathrm{F}_{\mathrm{s}}=$ fator de forma

O fator de profundidade $F_{o}$ é obtido pela altura da calha em relação à largura, calhas cuja altura é maior do que a largura têm vazão maior, visto que a pressão hidrostática aumenta com o aumento da lâmina de água. Desejável é uma calha de seção aproximadamente quadrada. Para $F_{o}$ aplica-se a Equação 6:

$$
F_{o}=(W / T)^{0,25}
$$

Equação (6)

onde,

W = altura da lâmina de água na vazão de projeto ou de emergência, e

$\mathrm{T}=$ largura da parte superior da calha

O fator de forma $F_{s}$ é derivado da relação da largura da base da calha "S" e da parte superior " $T$ ", idealmente $S=T$ e assim 0 fator $F_{S}=1$. Os valores de $F_{s}$ podem ser calculados pela Equação 7:

$\mathrm{F}_{\mathrm{S}}=-0,0612 \times(\mathrm{S} / \mathrm{T})^{4}+0,1832 \times(\mathrm{S} / \mathrm{T})^{3}-0,2705 \times(\mathrm{S} / \mathrm{T})^{2}+0,2581 \times(\mathrm{S} / \mathrm{T})+0,8903$ Equação (7)

$\mathrm{Na}$ segunda etapa deve-se observar o comprimento e a inclinação da calha, relacionados pela Equação 8:

$$
\mathrm{Q}=\mathrm{Q} \mathrm{L} \times \mathrm{FL}
$$

Conforme a norma EN 12056-3:2000 e DIN 1986-100:2008 o fator de comprimento " $F_{L}$ " é aplicado para calhas de comprimento maior do que 50 vezes o valor de "W", ou seja, a altura da lâmina de água na vazão de projeto, o fator considera a perda de carga por atrito típica de calhas compridas. O fator " $F_{L}$ " é dado pela Equação 9:

$$
F_{L}=0,000001 \times(L / W)^{2}-0,0015 \times(L / W)+1,062
$$

A norma EN 12056-3:2000 na página 15, fornece valores para $F_{L}$, para as calhas com inclinação maior do que $3 \mathrm{~mm} / \mathrm{m}$. A Tabela 3 (Friedrich 2020) fornece valores de vazões para calhas retangulares variando com diferentes valores de " $S$ ", "Z", bordo livre e alturas de " $W+W$ ".

\section{Drenagem de emergência}

Conforme já mencionado, as normas EN 12056-3:2000 e DIN 1986-100:2008 exigem que todas as calhas internas sejam providas de saídas de emergência, seja através de um tubo lateral (calhas com pouco comprimento) ou ralos de drenagem separados e ligados à tubulação específica, que em condições normais de operação (vazão de projeto) deve estar vazia.

A capacidade do sistema de drenagem de emergência é regulamentada pelas normas dos diferentes países, variando de 30-100\% da vazão de projeto. Na Figura 14 (esquerda) é mostrado um trecho de calha com ralo normal e de emergência e na Figura 14 (direita) uma calha seccionada. 
RICHERS, S. S.; SOWMY, D. S.

A importância do dimensionamento da calha interna de grandes coberturas

Tabela 3 - Vazões em $\mathrm{L} / \mathrm{S}$ para calhas retangulares

\begin{tabular}{ccccc}
\hline "S" largura em mm & "Z" altura em mm & Bordo livre & "W + We", em mm & Vazão QL, em L/S \\
\hline 50 & 50 & 25 & 25 & 0,2 \\
\hline 60 & 60 & 25 & 35 & 0,4 \\
\hline 80 & 80 & 25 & 55 & 1,1 \\
\hline 100 & 100 & 30 & 70 & 2,1 \\
\hline 150 & 150 & 45 & 105 & 5,7 \\
\hline 200 & 200 & 60 & 140 & 11,6 \\
\hline 250 & 250 & 75 & 175 & 20,3 \\
\hline 300 & 300 & 75 & 225 & 35,5 \\
\hline 350 & 350 & 75 & 55,9 \\
\hline 400 & 400 & 75 & 325 & 82,1 \\
\hline 450 & 450 & 75 & 375 & 114,1 \\
\hline 500 & 500 & 75 & 425 & 153,4 \\
\hline 600 & 500 & 75 & 425 & 184,1 \\
\hline 700 & 500 & 75 & 425 & 214,7 \\
\hline 800 & 500 & 75 & 425 & 245,4 \\
\hline 900 & 500 & 75 & 425 & 276,1 \\
\hline 1000 & 500 & 75 & 425 & 300,7 \\
\hline 1250 & 500 & 75 & 425 & 383,4 \\
\hline 1500 & 500 & 75 & 425 & 460,1 \\
\hline 2000 & 500 & 75 & 425 & 613,5 \\
\hline
\end{tabular}

Fonte: Traduzido de Friedrich (2020).

Figura 14 - Trecho de calha interna com ralo normal e de emergência (ao fundo) (esquerda) e trecho de calha segmentada (direita)

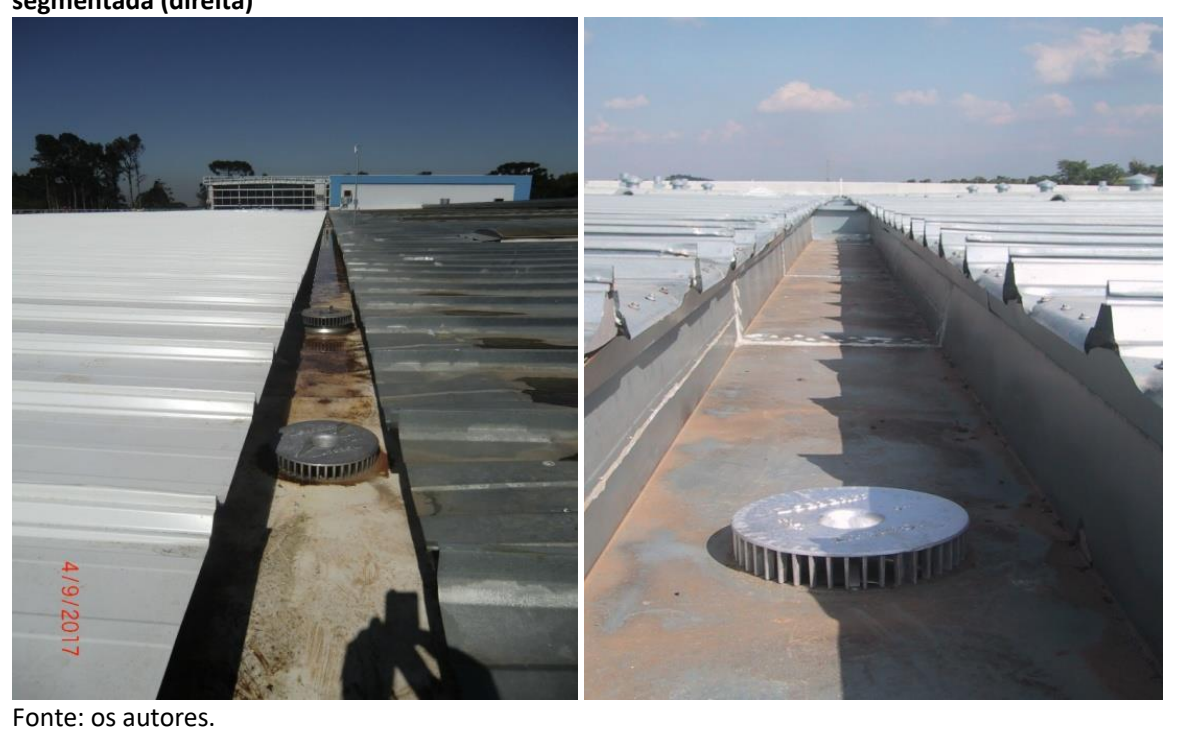

Na Figura 15, é visualizado o layout de um sistema de drenagem de emergência para calhas internas com duas alternativas de drenagem, externa ou interna.

Figura 15 - Drenagem de emergência para calhas internas - layout

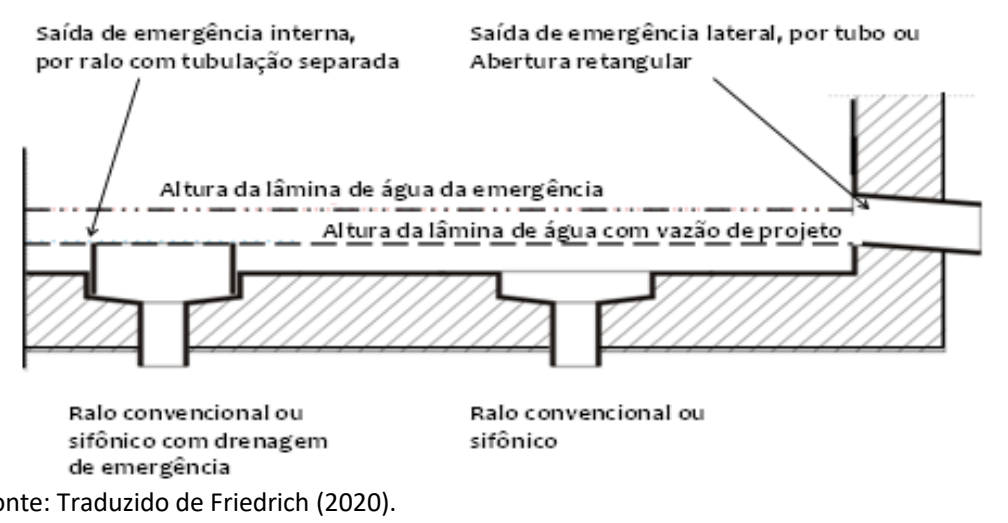


RICHERS, S. S.; SOWMY, D. S.

A importância do dimensionamento da calha interna de grandes coberturas

\section{Exercício projetual}

O exercício projetual deste artigo está descrito com detalhamento em Richers (2018). Será demonstrado o dimensionamento de uma calha interna conforme as normas internacionais, complementando o estudo comparativo dos sistemas de drenagem convencional e sifônico já mencionado anteriormente. Trata-se de um galpão industrial localizado na região de São Paulo, com precipitação pluviométrica de $191 \mathrm{~mm} / \mathrm{h}$, indicada pela NBR 10844:1989. O galpão apresenta uma calha interna conforme a Figura 16.

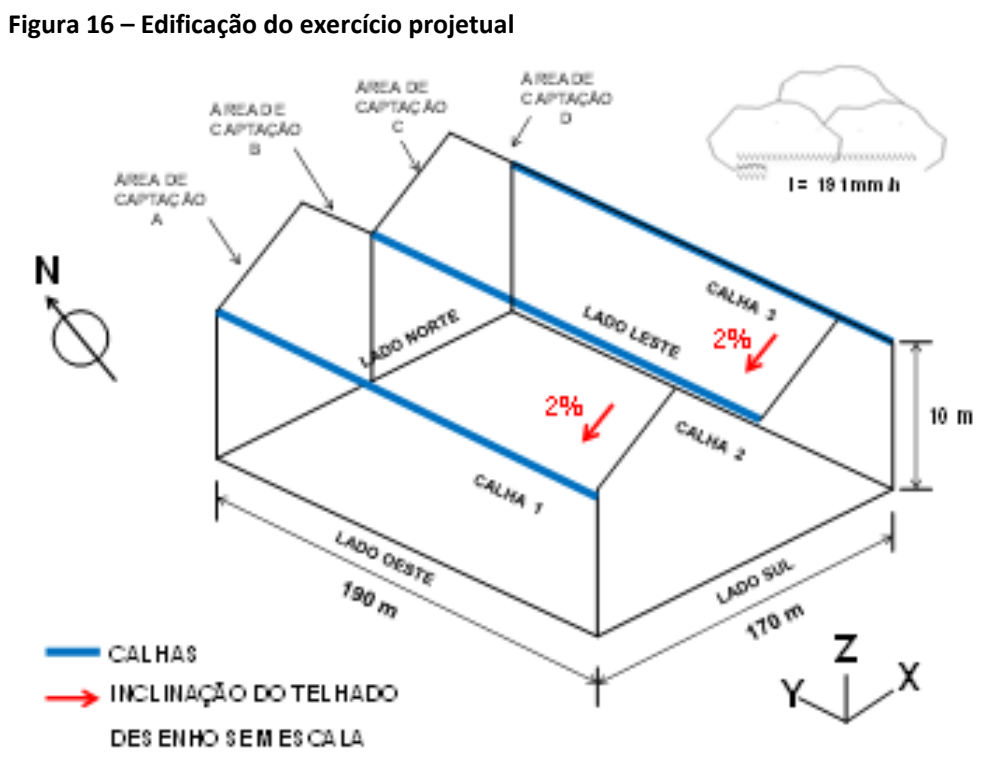

Fonte: Richers (2018).

Os dados que caracterizam a edificação são:

- comprimento da edificação = $190 \mathrm{~m}$;

- largura da edificação = $170 \mathrm{~m}$;

- altura da edificação até a calha, $\mathrm{H}_{\mathrm{t}}=10,0 \mathrm{~m}$;

- quatro telhados (águas) de 42,5 m de largura e $190 \mathrm{~m}$ de comprimento, ou seja, uma área de captação total de $32.300 \mathrm{~m}^{2}$, formada por quatro telhados de $8.075 \mathrm{~m}^{2}$;

- não há caixas de passagem internas;

- as prumadas devem estar nas bordas da edificação;

- os condutores de águas pluviais, verticais e horizontais, devem possibilitar a movimentação de equipamentos por meio de ponte rolante;

- as caixas de passagem externas estão 0,5 m abaixo do nível do piso e estão localizadas $2 \mathrm{~m}$ fora da edificação;

- três calhas (calha 1 externa capta $8.075 \mathrm{~m}^{2}$, calha 2 interna capta $16.150 \mathrm{~m}^{2}$ e calha 3 externa capta $\left.8.075 \mathrm{~m}^{2}\right)$;

- as calhas são de aço galvanizado e têm as seguintes medidas: calhas 1 e 3, externa, largura $80 \mathrm{~cm}$ e aba lateral de $45 \mathrm{~cm}$, a calha 2 interna têm largura de $100 \mathrm{~cm}$ e aba lateral $65 \mathrm{~cm}$;

- as calhas têm 0,5\% de inclinação; 
RICHERS, S. S.; SOWMY, D. S.

A importância do dimensionamento da calha interna de grandes coberturas

- telhados com 2\% de inclinação;

- intensidade pluviométrica para o local, com $\mathrm{T}=25$ anos, de acordo com a NBR 10.844:1989, Tabela, 5 é de $191 \mathrm{~mm} / \mathrm{h}$; e

- drenagem de emergência mínima de 30\% da vazão de projeto.

A cobertura da edificação tem $32.623 \mathrm{~m}^{2}$ e com a chuva de projeto de $191 \mathrm{~mm} / \mathrm{h}$ a vazão de cada uma das quatro águas é de $432,7 \mathrm{l} / \mathrm{s}$. As quatro águas têm dimensões idênticas, assim a calha interna deverá captar $865,4 \mathrm{~L} / \mathrm{s}$. A calha interna dimensionada pelo construtor da cobertura é uma calha interna com $100 \mathrm{~cm}$ de largura e aba lateral de 65 $\mathrm{cm}$. Deseja se verificar, com base nas normas EN 12056-3:2000 e DIN 1986-100:2008, se as medidas dessa calha são suficientes sem que haja transbordamento, em condições de vazão de projeto, conforme Figura 17.

Figura 17 - Corte da calha interna com medidas e altura da lâmina de água

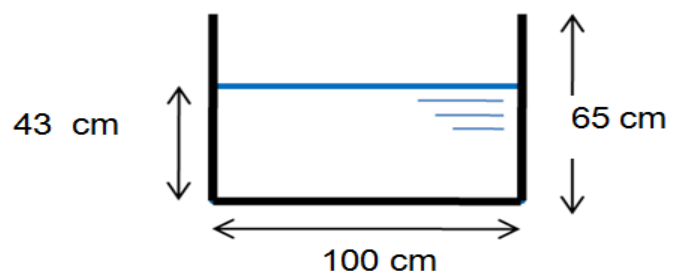

Fonte: os autores.

A altura da lâmina de água desta calha foi calculada pela NBR 10.844:1989 utilizando-se os ábacos e fórmulas que constam nesta norma. A drenagem da edificação foi estudada com os sistemas SCDAP e SSDAP, conforme Figura 18.

Figura 18 - Sistema convencional (SCDAP) (esquerda) e Sistema sifônico (SSDAP) (direita)
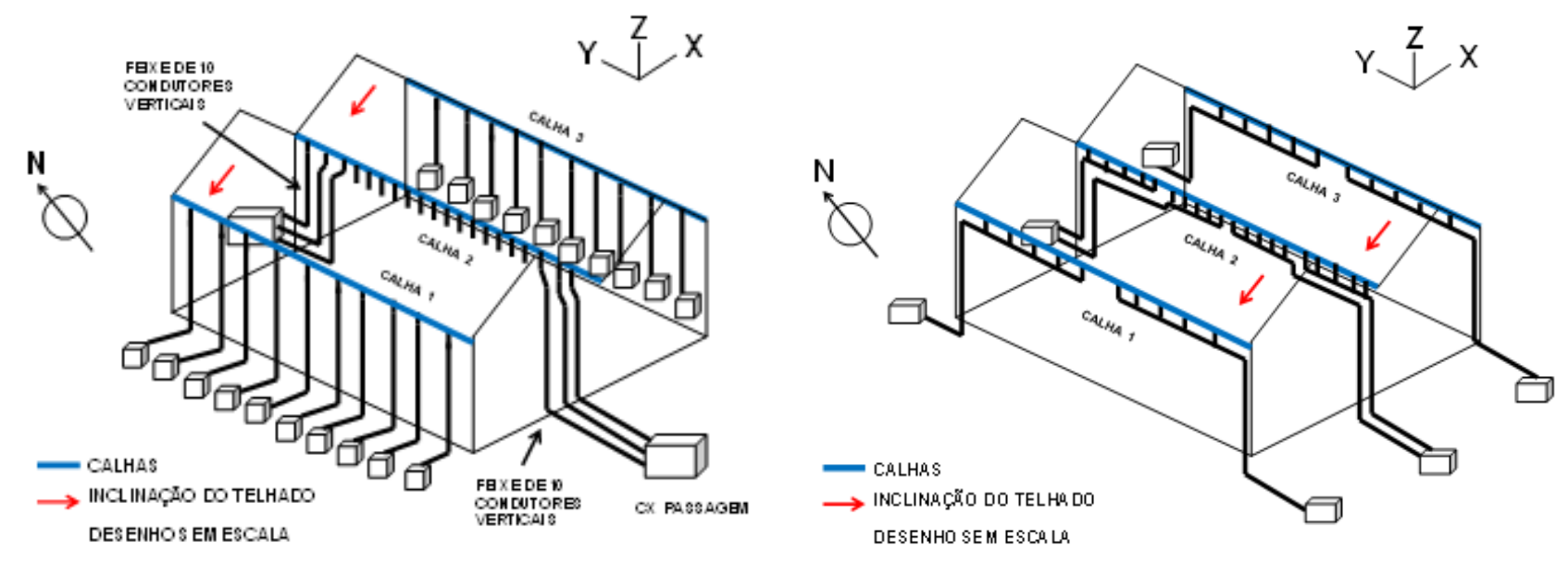

Fonte: Richers (2018).

Aplicando-se uma drenagem de emergência de apenas 30\% $(12,9 \mathrm{~cm})$ obtém-se uma altura da lâmina de água com vazão de projeto e de emergência de $55,9 \mathrm{~cm}(43 \mathrm{~cm}+$ 12,9 cm). Segundo a EN 12056-3:2008 e a DIN 1986-100:2008, para uma altura da lâmina de água de $43 \mathrm{~cm}$ deve-se usar um bordo livre de $7,5 \mathrm{~cm}$. A altura da aba lateral da calha, conforme as normas mencionadas anteriormente, deve ser de $43 \mathrm{~cm}+12,9 \mathrm{~cm}+$ $7,5 \mathrm{~cm}=63,5 \mathrm{~cm}$. A NBR 10844:1989 fornece valores de precipitação pluviométrica para um período de retorno $\mathrm{T}=25$ anos, enquanto que, para calhas internas, as normas EN 12056-3:2000 e DIN 1986-100:2008 exigem o uso de um período de retorno de $\mathrm{T}=100$ anos. Neste exercício projetual não foi utilizado nenhum fator de segurança já que a localidade da edificação e a precipitação pluviométrica do local eram conhecidas. 
Conclui-se, portanto, que a calha interna deste exercício projetual, com uma altura da aba lateral é de $65 \mathrm{~cm}$ é adequada para uma drenagem de emergência de $30 \% \mathrm{em}$ relação à vazão de projeto atendendo às normas EN 12056-3:2000 e DIN 1986100:2008. Entretanto, para drenagens de emergência acima de $30 \%$ em relação à vazão de projeto, poderá haver um transbordamento.

\section{Conclusões}

Sintetizando os resultados alcançados, pode-se dizer que o dimensionamento de calhas internas segundo descrito nas normas EN 12056-3:2000, a DIN 1986-100:2008 e literatura consultada para este artigo, indica que fatores de segurança, valores de precipitação pluviométrica com tempo de retorno de 100 anos e bordo livre devem ser atendidos. Correspondentemente, as medidas calculadas para uma calha interna devem ser discutidas com os construtores das coberturas e calhas. Poderá haver limitações de espaço (vertical e horizontal) para acomodar a calha dimensionada, além de possível necessidade de seccionamento das calhas por motivos construtivos. Idealmente, o projeto da cobertura deve desde o início considerar as medidas da calha interna.

Assim, contribui-se para que o investidor ou o construtor verifique a melhor viabilidade econômica da construção da cobertura de uma edificação como apresentado no exercício projetual, de acordo com as alternativas de construção: i) Com duas ou quatro águas, dependendo evidentemente das medidas da edificação; ii) Inclinação da cobertura; iii) Velocidade de escoamento das águas pluviais em cima da cobertura e iv) Custos para a construção da cobertura em si.

Descrições na literatura, como Piroglu (2014), referem-se às calhas internas que transbordam com danos materiais consideráveis. As possíveis causas vão desde um subdimensionamento em relação às recomendações descritas nas normas, já citadas, até uma adaptação das calhas ao espaço remanescente após o projeto da cobertura. $O$ dimensionamento de calhas internas deve ser feito em conjunto com o dimensionamento do restante do sistema de drenagem de águas pluviais (ralos de captação, tubulação e conexões) e a drenagem externa da edificação até o descarte das águas pluviais num corpo receptor ou, se houver reuso das águas pluviais, até a cisterna de reuso.

\section{Nota}

Este artigo é uma versão estendida do artigo "Sistema sifônico de drenagem de águas pluviais - tecnologia para grandes coberturas industriais e comerciais - estudo de caso" (RICHERS; SOWMY, 2019) apresentado pelos autores no II WORKSHOP DE TECNOLOGIA DE PROCESSOS E SISTEMAS CONSTRUTIVOS.

\section{Referências}

AMERICAN SOCIETY OF MECHANICAL ENGINEERS. ASME A112.6.9-2005. Siphonic roof drains. New York: ASME, 2005 .

AMERICAN SOCIETY OF PLUMBING ENGINEERS. ASPE 45:2018: Siphonic roof drainage. Rosemont: ASPE, 2013.

AMERICAN SOCIETY FOR TESTING MATERIALS. ASTM F 2021-2006: Standard guide for design and installation of plastic siphonic roof drainage systems. West Conshohocken: ASTM, 2006.

ARTHUR, S.; SWAFFIELD, J. A. Understanding siphonic rainwater drainage systems. In: INTERNATIONAL SYMPOSIUM ON WATER SUPPLY AND DRAINAGE FOR BUILDINGS, 25., Edinburgh, 1999. Proceedings [...]. Delf: CIB Wo62, 1999. B1. 
RICHERS, S. S.; SOWMY, D. S.

A importância do dimensionamento da calha interna de grandes coberturas

ARTHUR, S.; WRIGHT, G. B. Siphonic roof drainage systems - priming focused design. Building and Environment, Edinburgh, v. 42, n. 6, p. 2421-2431, 2007. DOI: https://doi.org/10.1016/j.buildenv.2006.08.021

ASSOCIAÇÃO BRASILEIRA DE NORMAS TÉCNICAS. NBR 10.844: Instalações prediais de águas pluviais. Rio de Janeiro: ABNT, 1989.

BEECHAM, S.; LUCKE, T. Influence of channel geometry on water levels above siphonic roof outlets. Building Service Engineering Research and Technology, v. 35, n. 1, p. 83-98, 2012. DOI:

https://doi.org/10.1177\%2F0143624412467544

BOWLER, R.; ARTHUR, S. Siphonic roof rainwater drainage - design considerations. In: INTERNATIONAL SYMPOSIUM ON WATER SUPPLY AND DRAINAGE FOR BUILDINGS, 25., 1999, Edinburgh. Proceedings [... ]. Delf: CIB Wo62, 1999. A 3.

BRAMHALL, M. A. The performance of siphonic rainwater outlets within gutters. 2005. Thesis (PhD) - University of Sheffield, 2005.

BRAMHALL, M. A.; SAUL, A. J. Examination of the performance of syphonic rainwater outlets. In: INTERNATIONAL SYMPOSIUM ON WATER SUPPLY AND DRAINAGE FOR BUILDINGS, 1998, Rotterdam. Proceedings [...]. Delf: CIB Wo62, 1998.

BRITISH STANDARDS INSTITUTE. BS 8490:2007: Guide to siphonic roof drainage systems. London: BSI, 2007.

DEPARTAMENT OF PLANNING AND LOCAL GOVERNMENT. Siphonic roofwater systems. In: Departament of Planning and Local Government. Water sensitive urban design technical manual for the Greater Adelaide Region. Adelaide: Government of South Australia, 2010, cap. 16, p. 16-42.

DEUTSCHES INSTITUT FÜR NORMUNG. EN 12.056-3: Schwerkraftentwässerungsanlagen innerhalb von Gebäuden. Teil 3: Dachentwässerung, Planung und Bemessung. Deutsche Fassung. EN 12.056-3:2000. DIN. Januar. 2001.

DEUTSCHES INSTITUT FÜR NORMUNG. DIN 1986-100: Entwässerungsanlagen für Gebäude und Grundstücke -Teil 100: Bestimmungen in Verbindung mit DIN EN 752 und DIN EN 12.056. Mai. 2008.

FRIEDRICH, M. Basiswissen für Dachentwässerung. Markus Friedrich Datentechnik, Berlin, Junho 2020. Disponível em: https://www.friedrich-datentechnik.de/download/basiswissen/Basiswissen-Drain.pdf. Acesso em: 20.08.2020 12:30.

LUCKE, Terry. The role of air entrainment in the performance of siphonic roof drainage systems. $2009.228 \mathrm{f}$. Tese (Doutorado) - University of South Australia, Adelaide, 2009.

MAY, R. W. P. The design of conventional and siphonic roof-drainage systems. Water and Environment Journal, v. 11, n. 1, p. 56-60, feb. 1997.

MAY, R. W. P. Design criteria for siphonic roof drainage systems. Wallingford: HRS, 2004. (Report SR 654).

PEREIRA, João Pedro Dias de Nunes. Sistemas Prediais Não Tradicionais de Drenagem de Águas Residuais Pluviais: sistemas sifónicos ou em pressão. 2012. 96 f. Dissertação (Mestrado) - Curso de Engenharia Civil, Faculdade de Engenharia da Universidade do Porto, Porto, 2012.

PIROGLU, Filiz et al. Site investigation of damages occurred in a steel space truss roof structure due to ponding. Engineering Failure Analysis. Istanbul, v. 36, p. 301-313. out. 2013. DOI: https://doi.org/10.1016/j.engfailanal.2013.10.018

RATTENBURY, J. Fundamentals of siphonic roof drainage. PM Engineer, p. 52-58, mar. 2001. 
RICHERS, S. S.; SOWMY, D. S.

A importância do dimensionamento da calha interna de grandes coberturas

RICHERS, Sabine Schmalz. Sistema Sifônico de Drenagem de Águas Pluviais em Grandes Coberturas - Estudo de Caso. 2018. 214 f. Dissertação (Mestrado) - Curso de Habitação: Planejamento e Tecnologia, Instituto de Pesquisas Tecnológicas do Estado de São Paulo, São Paulo, 2018. Disponível em:

http://cassiopea.ipt.br/teses/2018_HAB_Sabine_Richers.pdf. Acesso em: 03 out. 2021.

RICHERS, S. S.; SOWMY, D. S.. Sistema sifônico de drenagem de águas pluviais - tecnologia para grandes coberturas industriais e comerciais - estudo de caso. In: WORKSHOP DE TECNOLOGIA DE PROCESSOS E SISTEMAS CONSTRUTIVOS, 2., 2019, São Paulo. Anais [...]. São Paulo: IPT, 2019. p. 1-7. Disponível em: https://eventos.antac.org.br/index.php/tecsic/article/view/398. Acesso em: 8 out. 2021.

RICKMANN, Bernhard. Gebäude und Grundstücksentwässerung: Schadensbilder. Münster: Fachhochschule Münster, 2019. Color.

SOMMERHEIN, P. Design parameters for roof drainage systems. In: INTERNATIONAL SYMPOSIUM ON WATER SUPPLY AND DRAINAGE FOR BUILDINGS, 25., 1999, Edinburgh. Proceedings [... ]. Delf: CIB W062, 1999. A4.

VEREIN DEUTSCHER INGENIEURE. VDI 3806:2000: Roof drainage with siphonic system. April 2000.

VERSTRATEN, L., et al. Sensitivity of Australian roof drainage structures to design rainfall variability and climate change. Building and Environment, v.161, 106230, 2019. DOI: https://doi.org/10.1016/J.BUILDENV.2019.106230

\section{Sabine schmalz Richers}

Engenheira Civil formada pela Universidade Presbiteriana Mackenzie. Mestre pelo Instituto de Pesquisas Tecnológicas do Estado de São Paulo. Autônomo. Endereço postal: Av. Prof. Almeida Prado, 532 CX11 Butantã, São Paulo, SP - Brasil. CEP 05508-901

\section{Daniel Setrak Sowmy}

Engenheiro Civil formado pela Escola Politécnica da Universidade de São Paulo. Doutorado pela mesma instituição. Atualmente é pesquisador do Instituto de Pesquisas Tecnológicas do Estado de São Paulo e professor do Departamento de Engenharia Civil da Escola Politécnica da USP. Endereço postal: Av. Prof. Almeida Prado, 532 CX11 Butantã, São Paulo, SP - Brasil. CEP 05508-901 